\title{
DIVERGENCE BETWEEN ARTERIAL PERFUSION AND FATIGUE RESISTANCE IN SKELETAL MUSCLE IN THE METABOLIC SYNDROME
}

\author{
Jefferson C. Frisbee ${ }^{1}$, Adam G. Goodwill ${ }^{1}$, Joshua T. Butcher ${ }^{1}$, and I. Mark Olfert ${ }^{2}$ \\ ${ }^{1}$ Department of Physiology and Pharmacology Center for Cardiovascular and Respiratory \\ Sciences, West Virginia University HSC, Morgantown, WV \\ ${ }^{2}$ Division of Exercise Physiology Center for Cardiovascular and Respiratory Sciences, West \\ Virginia University HSC, Morgantown, WV
}

\begin{abstract}
The metabolic syndrome is associated with elevated peripheral vascular disease risk, characterized by mismatched blood flow delivery/distribution and local metabolism. The obese Zucker rat (OZR) model of the metabolic syndrome exhibits myriad vascular impairments, although their integrated impact on functional hyperemia remains unclear. In this study, arterial pressor responses and skeletal muscle perfusion were assessed in lean Zucker rats (LZR) and OZR during adrenergic stimulation (phenylephrine), challenge with thromboxane (U46619) and endotheliumdependent dilation (methacholine). OZR were hypertensive versus LZR, but this was abolished by adrenoreceptor blockade (phentolamine); pressor responses to U46619 were similar between strains and were abolished by blockade with the $\mathrm{PGH}_{2} / \mathrm{TxA} \mathrm{A}_{2}$ receptor antagonist, SQ-29548. Depressor reactivity to methacholine was impaired in OZR, but was improved by antioxidant treatment (TEMPOL). Across levels of metabolic demand, blood flow to in situ gastrocnemius muscle was restrained by adrenergic constriction in OZR, although this diminished with increased demand. $\mathrm{O}_{2}$ extraction, reduced in OZR vs. LZR across levels of metabolic demand, was improved by TEMPOL or SQ-29548; treatment with phentolamine did not impact extraction and neither TEMPOL nor SQ-29548 improved muscle blood flow in OZR. While $\mathrm{VO}_{2}$ and muscle performance were consistently reduced in OZR vs. LZR, treatment with all three agents improved outcomes, while treatment with individual agents was less effective. These results suggest that contributions of vascular dysfunction to perfusion, $\mathrm{VO}_{2}$ and muscle performance are spatially distinct, with adrenergic constriction impacting proximal resistance and endothelial dysfunction impacting distal microvessel-tissue exchange. Further, these data suggest that increasing skeletal muscle blood flow in OZR is not sufficient to improve performance, unless distal perfusion inhomogeneities are rectified.
\end{abstract}

\section{Keywords}

rodent models of obesity; skeletal muscle blood flow regulation; models of peripheral vascular disease; blood flow heterogeneity; vascular dysfunction

\footnotetext{
Address for Correspondence: Jefferson C. Frisbee, Ph.D. Center for Cardiovascular and Respiratory Sciences Department of Physiology and Pharmacology West Virginia University Health Sciences Center; 3152 HSN 1 Medical Center Drive Morgantown, WV 26506 Phone: (304) 293-6527 Fax: (304) 293-5513 jfrisbee@hsc.wvu.edu.
} 


\section{INTRODUCTION}

One of the hallmark characteristics in the development of the metabolic syndrome, with its constituent systemic pathologies of obesity, insulin resistance/type II diabetes mellitus, atherogenic dyslipidemia and hypertension, is the substantially increased risk for the progressive evolution of peripheral vascular disease (Cannon, 2008; Ford and Mokdad, 2008; Jones 2008; Obunai et al. 2007). While this can possess atherosclerotic or nonatherosclerotic elements in its constitution (with distinct etiological characteristics and outcomes), one of the defining elements of peripheral vascular disease (PVD) is an evolving inability to effectively match tissue perfusion with local metabolic demand, an observation routinely demonstrated in both humans and in multiple animal models of the metabolic syndrome (Baron, 2002; He et al. 1995; Nicholson et al. 1992; Ruiter et al. 2010; Wolfram et al. 2001). While this has been identified across numerous organs/tissues, we have demonstrated reduced bulk blood flow to in situ gastrocnemius muscle of the obese Zucker rat (OZR) across ranges of demand from rest to near maximum metabolic intensity (Frisbee et al. 2009; Frisbee 2005; 2004; 2003).

In OZR, a model of the metabolic syndrome which derives its genesis through chronic hyperphagia as a result of a severe receptor-based leptin resistance (Guerre-Millo, 1997; Williams et al. 2001), the basic contributing mechanisms underlying the compromised perfusion and hyperemic responses may include: 1) enhanced adrenergic constrictor reactivity and signaling of skeletal muscle arterioles (Frisbee, 2004; Naik et al. 2006; Stepp and Frisbee, 2002), 2) a widespread impairment to arteriolar dilator reactivity, primarily centered around compromised endothelial function (Bouvet et al. 2007; Frisbee et al. 2009; Goodwill et al. 2008; Katakam et al. 2009; Lu et al. 2010), and 3) structural remodeling of the microvasculature (Bovet et al. 2007; Goodwill et al. 2009; Lu et al. 2010; Stepp et al. 2004), including a reduced wall distensibility of the resistance arterioles (predominantly contributing to an elevated vascular resistance) and a rarefaction of the distal microvasculature (predominantly contributing to impairments to mass transport and exchange in the microenvironments). With these elements in place, a progressive deterioration in tissue perfusion develops which can, and ultimately does, negatively impact the ability of the skeletal muscle to resist fatigue (Frisbee, 2006; 2004).

However, recent data suggests that a more complex relationship than has been previously understood may exist with regard to the linkages between skeletal muscle perfusion and fatigue resistance within the metabolic syndrome. Specifically, we have recently provided initial evidence that multiple pathways which derange the normal patterns of skeletal muscle arteriolar reactivity integrate to impair not only vascular dilation in a metabolic demanddependent fashion, but also that these can contribute to perfusion heterogeneity at microvascular bifurcations which could represent a significant contributor to the compromised ability of microvascular networks to match perfusion to local metabolic demand (Frisbee et al. 2009).

As a result of these recent observations, there is an immediate need for a more accurate understanding of the relationships between the perfusion to, and the performance of, skeletal muscle within the setting of the metabolic syndrome. Given that the metabolic syndrome represents a condition which strongly predisposes individuals to an elevated risk of PVD, which can be defined as a condition wherein the perfusion:metabolic demand matching can be substantially impaired, the translational importance of the thorough understanding of how perfusion and muscle performance are intertwined in this pathological setting is imperative. The purpose of this study is to thoroughly evaluate functional outcomes (performance) in skeletal muscle and to provide a framework for future interrogation into the detailed relationships between vascular function, perfusion and skeletal muscle performance 
outcomes. This study was designed to provide a rigorous test of the hypothesis that functional hyperemia is constrained within skeletal muscle of OZR owing to the combined impact of adrenergic constraint and endothelial dysfunction, each of which acts to either inappropriately increase, or prevent reductions in, the resistance to skeletal muscle blood flow over a range of imposed metabolic demand.

\section{MATERIALS AND METHODS}

\section{Animals}

15-17 week old male lean Zucker rats (LZR) and OZR fed standard chow and tap water ad libitum were used for all experiments. Data describing the baseline characteristics of LZR and OZR in the present study are presented in Table 1. At this age range, OZR were significantly heavier than age-matched LZR and also demonstrated fasting (overnight) hyperglycemia, hyperinsulinemia, elevated plasma triglyceride levels and moderate hypertension. Rats were housed in animal care facility at either the Medical College of Wisconsin or at the West Virginia University Health Sciences Center, and all protocols received prior IACUC approval. Rats were anesthetized with injections of sodium pentobarbital $\left(50 \mathrm{mg} \bullet \mathrm{kg}^{-1}\right.$ i.p.), and received tracheal intubation to facilitate maintenance of a patent airway. In all rats a carotid artery and an external jugular vein were cannulated for determination of arterial pressure and for intravenous infusion of additional substances as necessary (e.g., anesthetic, heparin, etc.).

\section{Preparation of In Situ Blood-Perfused Skeletal Muscle}

In all LZR and OZR, the left gastrocnemius muscle was isolated in situ (Frisbee, 2003). Briefly, the left leg received a medial incision from the calcaneus to the femoral triangle, and all muscles, vessels and connective tissue overlaying gastrocnemius muscle were removed, thus exposing the gastrocnemius muscle, its vascular supply, and the sciatic nerve. The nerve was isolated and utilized for initiating muscle contraction via a stimulating electrode attached to an electrical stimulator (Grass SD9). Branches from the femoral artery that did not perfuse the gastrocnemius muscle directly were ligated or cauterized, depending on size and location. A microcirculation flow probe (Transonic) was placed around the femoral artery, immediately distal to its origin from the iliac artery, in order to measure blood flow to the gastrocnemius muscle. As a final step, a 24 gauge angiocatheter was inserted into the femoral vein to allow for sampling of venous blood from the contracting muscle. The entire preparation was covered in PSS-soaked gauze and plastic film to minimize evaporative water loss and was placed under a lamp to maintain temperature at $37^{\circ} \mathrm{C}$. At this time, heparin $(500 \mathrm{U} / \mathrm{kg})$ was infused via the jugular vein to prevent blood coagulation.

\section{Section One: Arterial Pressor and Hindlimb Perfusion Responses}

Following the complete surgical preparation of the rats, it was necessary to validate the effectiveness of the experimental conditions that were to be utilized for the subsequent interrogations of skeletal muscle perfusion and fatigue resistance relationships. For these procedures, rats received an intravenous infusion of the $\alpha_{1} / \alpha_{2}$ adrenoreceptor antagonist phentolamine (10 mg/kg; followed by 30 minutes of equilibration), the superoxide dismutase mimetic 4-hydroxy-2,2,6,6-tetramethylpiperidine-N-oxyl (TEMPOL; $50 \mathrm{mg} / \mathrm{kg}$; followed by 45 minutes of equilibration), or the $\mathrm{PGH}_{2} / \mathrm{TxA}_{2}$ receptor antagonist SQ-29548 $(10 \mathrm{mg} / \mathrm{kg}$; followed by 30 minutes of equilibration) in order to remove the influences of adrenergic tone, vascular oxidant stress and influence of vascular sources of $\mathrm{TxA}_{2}$ from the system, respectively. Following treatment of the individual rats with phentolamine, TEMPOL or SQ-29548, each animal was challenged with an intravenous infusion of the $\alpha-$ adrenoreceptor agonist phenylephrine $(10 \mu \mathrm{g} / \mathrm{kg})$, the endothelium-dependent nitric oxide 
donor methacholine $(10 \mu \mathrm{g} / \mathrm{kg})$ or the TxA 2 mimetic U46619 $(10 \mu \mathrm{g} / \mathrm{kg})$. Alterations in mean arterial pressure and femoral artery perfusion were monitored following agonist infusion in order to determine peak responses and the time to restoration of baseline (pretreatment) conditions. All infused intravenous doses of drugs were corrected for differences in circulating blood volume between LZR and OZR at this age (Frisbee, 2006; Schreihofer et al. 2005).

\section{Section Two: Responses of Contracting In Situ Skeletal Muscle}

Following validation of the actions of phentolamine, TEMPOL or SQ-29548 and restoration of baseline conditions, the gastrocnemius muscle was stimulated to perform (via the sciatic nerve) bouts of isometric twitch contractions $(1,3$, or $5 \mathrm{~Hz}, 0.4 \mathrm{~ms}$ duration, $5 \mathrm{~V})$ for 3 minutes followed by 15 minutes of self-perfused recovery, with arterial pressure and femoral artery blood flow continuously monitored. Data were collected under control conditions and following treatment of the rats with phentolamine, TEMPOL or SQ-29548, as described above.

\section{Data Calculations}

In specific experiments, $200 \mu \mathrm{l}$ blood samples were drawn from the carotid artery cannula and femoral vein angiocatheter immediately prior to and following completion of, the muscle contraction periods. Samples were stored on ice until they were processed for blood gas pressures, percent oxygen saturation and hemoglobin concentration using a Corning Rapidlab 248 blood gas analyzer. Muscle perfusion, arterial pressure, and bulk blood flow through the femoral artery were monitored for one minute prior to muscle contractions and throughout the contraction period using a Biopac MP150 with Acqknowledge data acquisition software at a $50 \mathrm{~Hz}$ sampling frequency. Muscle perfusion and performance data after three minutes of contraction were normalized to gastrocnemius mass, which was not different between LZR $(2.18 \pm 0.09 \mathrm{~g})$ and OZR $(2.06 \pm 0.10 \mathrm{~g})$. Oxygen content within the blood samples was determined using the following standard equation:

$$
\mathrm{C}_{x} \mathrm{O}_{2}=\left(1.39 \times[\mathrm{Hb}] \times \% \mathrm{SatO}_{2}\right)+\left(0.003 \times P_{x} \mathrm{O}_{2}\right)
$$

Where $C_{x} O_{2}$ and $P_{x} O_{2}$ represent the total content $(\mathrm{ml} / \mathrm{dL})$ or partial pressure of oxygen $(\mathrm{mmHg})$, respectively, of arterial or venous blood (denoted simply as ' $\mathrm{x}$ '). $[\mathrm{Hb}]$ represents hemoglobin concentration within the blood sample $(\mathrm{g} / \mathrm{dL}) ; \% \mathrm{O}_{2}$ Sat represents the percentage oxygen saturation of the hemoglobin and 1.39 and 0.003 represent constants describing the amounts of bound and dissolved oxygen in blood. Oxygen uptake across the gastrocnemius muscle was calculated using the Fick equation:

$$
\dot{V} \mathrm{O}_{2}=\dot{Q} \times\left(\mathrm{CaO}_{2}-\mathrm{CvO}_{2}\right)
$$

where $\dot{V} \mathrm{O}_{2}$ represents oxygen uptake by the gastrocnemius muscle, $\dot{Q}$ represents femoral artery blood flow (ml/g/min), and $\mathrm{CaO}_{2}$ and $\mathrm{CvO}_{2}$ represent arterial and venous oxygen content, respectively. Perfusion resistance across gastrocnemius muscle was calculated as the quotient of mean arterial pressure and muscle blood flow. Muscle $\mathrm{O}_{2}$ conductance $\left(\mathrm{DmO}_{2}\right)$ was calculated using Fick's law of diffusion as a simple model of $\mathrm{O}_{2}$ flux to the working muscle,

$$
\dot{V} \mathrm{O}_{2}=\mathrm{DmO}_{2}\left(P \bar{c} \mathrm{O}_{2}-\mathrm{PmitoO}_{2}\right)
$$


where $\mathrm{DmO}_{2}$ is the diffusing capacity of $\mathrm{O}_{2}$ at the muscle $(\mathrm{ml} / \mathrm{min} / \mathrm{mmHg} / \mathrm{mg}$ muscle), $P \bar{c} O_{2}$ is the mean capillary $\mathrm{PO}_{2}(\mathrm{mmHg})$, and $\mathrm{Pmito}_{2}$ is average mitochondrial $\mathrm{PO}_{2}$ (mmHg) (Kurdak et al. 1996; Roca et al. 1989). Estimation of $P \bar{c} O_{2}$ is based on a numerical (Bohr) integration procedure that uses a single parameter for tissue diffusing capacity-to-muscle blood flow ratio $\left(\mathrm{DO}_{2} / \mathrm{QT}\right)$, which is assumed to be constant along the capillary, where $\mathrm{DO}_{2} / \mathrm{QT}$ is varied iteratively until the calculated end-capillary $\mathrm{PO}_{2}$ matches the measured venous $\mathrm{PO}_{2}$ to within $0.1 \mathrm{mmHg}$ (Kurdak et al. 1996; Roca et al. 1989). Mean capillary $\mathrm{PO}_{2} \mathrm{P}_{\bar{c}} \mathrm{O}_{2}$ is then a time-weighted average of all computed $\mathrm{PO}_{2}$ values along the capillary based on the initial measured arterial and venous $\mathrm{PO}_{2}$ values. Explicit assumptions in making the $\mathrm{DmO}_{2}$ calculation are that, 1) mitochondrial $\mathrm{PO}_{2}$ is negligibly small (i.e. $\mathrm{PmitoO}_{2}=0 \mathrm{mmHg}$ ) at maximal or near maximal exercise, and that 2) the only explanation of $\mathrm{O}_{2}$ remaining in the femoral venous blood is diffusion limitation of $\mathrm{O}_{2}$ efflux from the muscle microcirculation (Wagner, 1992). Accordingly, perfusional or diffusional shunts are considered negligible, and we only calculate $\mathrm{DmO}_{2}$ for data obtained at maximal or near maximal exercise (i.e. electrical stimulation at $5 \mathrm{~Hz}$ ). For all calculations we used hemoglobin of $15 \mathrm{gm} / \mathrm{dL}$ and $\mathrm{p} 50$ of $26.8 \mathrm{mmHg}$.

\section{Statistical Analyses}

Statistically significant differences in determined results were assessed using either Student's $t$-test or analysis of variance (ANOVA), with Student-Newman-Keul's post-hoc test as needed. In all cases, $p<0.05$ was taken to reflect statistical significance. All data are presented as mean $\pm \mathrm{SE}$.

\section{RESULTS}

Data describing the animals under investigation in the current study are summarized in Table 1. At 15-17 weeks of age, OZR were dramatically heavier than LZR, and demonstrated a significant impairment to glycemic control, dyslipidemia, and chronic elevations in vascular oxidant stress.

Figure 1 summarizes the impact of challenge of LZR and OZR with phenylephrine (with and without pre-treatment with phentolamine) on arterial pressure (Panel A), femoral artery blood flow (Panel B) and vascular resistance (Panel C) in LZR and OZR. In response to intravenous infusion of the adrenoreceptor agonist, mean arterial pressure was significantly increased in both strains, although the magnitude of this increase was similar between LZR $(67 \pm 9 \mathrm{mmHg})$ and OZR $(72 \pm 12 \mathrm{mmHg})$. Pre-treatment of animals with phentolamine reduced arterial pressure in both strains to a similar level and abolished pressor responses to infused phenylephrine (Panel A). Femoral artery blood flow in OZR was not significantly different as compared to LZR under control conditions, and challenge with phenylephrine infusion resulted in a mild, but variable, reduction in blood flow in both strains (Panel B). Following treatment with phentolamine, femoral artery blood flow was mildly elevated to similar levels between LZR and OZR, and infusion of phenylephrine was without effect. Vascular resistance, elevated in OZR versus LZR under control conditions, increased significantly in both strains following infusion of phenylephrine (Panel C), although this response was enhanced in OZR $[347 \pm 42 \mathrm{mmHg} /(\mathrm{ml} / \mathrm{g} / \mathrm{min})]$ as compared to LZR $[187 \pm 30$ $\mathrm{mmHg} /(\mathrm{ml} / \mathrm{g} / \mathrm{min})]$. Treatment of rats with phentolamine lowered resistance in both strains to a similar level, and blocked the overwhelming majority of the phenylephrine-induced increases in vascular resistance.

The impact of challenging the animal with the $\mathrm{TxA}_{2}$ analog $\mathrm{U} 46619$ and the effectiveness of blockade of the $\mathrm{PGH}_{2} / \mathrm{TxA}_{2}$ receptors with SQ-29548 is summarized in Figure 2. Infusion of U46619 increased arterial pressure in both strains, although the magnitude of this effect 
was very similar between LZR and OZR (Panel A). While blockade of $\mathrm{PGH}_{2} / \mathrm{TxA}_{2}$ receptors had no discernible impact on arterial pressure, it abolished the pressor response to U46619 in both strains. Infusion of U46619 (either with or without pre-treatment with SQ-29548) had no impact on bulk blood flow through the femoral artery in either LZR or OZR (Panel B). Treatment of rats with U46619 resulted in a similar, significant increase in vascular resistance in both strains, and this response was abolished by pre-treatment with SQ-29548 (Panel C).

Figure 3 presents data describing the impact of both infusion of methacholine and the effects of pre-treatment with TEMPOL on arterial pressure (Panel A), femoral artery blood flow (Panel B) and vascular resistance across the gastrocnemius muscle (Panel C) in LZR and OZR. In LZR, challenge with methacholine caused a rapid, significant depressor response that was unaffected by pre-treatment with TEMPOL. In contrast, infusion of methacholine in OZR did not significantly reduce arterial pressure, while pre-treatment of rats with TEMPOL improved the depressor response (Panel A). In preliminary studies, treatment of either LZR or OZR with the nitric oxide synthase inhibitor L-NAME $(100 \mathrm{mg} / \mathrm{kg})$ prevented the depressor effects of methacholine under any condition ( $\triangle \mathrm{MAP}$ from control in LZR+LNAME $=-3.5 \pm 3.6 \mathrm{mmHg}$; ( $\triangle \mathrm{MAP}$ from control in OZR+L-NAME $=+1.4 \pm 4.1 \mathrm{mmHg}$ ). In LZR, infusion of methacholine resulted in an increased femoral artery blood flow, a response not identified in OZR. This effect was not altered in LZR following pre-treatment with TEMPOL, although it was increased in OZR to the point of reaching statistical significance (Panel B). Similarly, methacholine infusion resulted in a decreased vascular resistance in LZR only (with or without TEMPOL treatment), while methacholine-induced reductions in resistance in OZR were identified following pre-treatment with TEMPOL (Panel C).

The hemodynamic characteristics within gastrocnemius muscle of OZR and LZR under resting conditions in the present study are summarized in Figure 4. The decreased femoral artery blood flow in OZR as compared to LZR at rest was eliminated following treatment with phentolamine, although treatment with either TEMPOL or SQ-29548 was without effect (Panel A). Incorporating arterial pressure, the elevation in vascular resistance across the gastrocnemius in OZR was corrected following infusion of phentolamine, while treatment with TEMPOL or SQ-29548 provided no discernible benefit (Panel B). Under resting conditions, the extraction of oxygen from arterial to venous blood was significantly reduced in OZR versus LZR and, in contrast to the previous panels, only treatment with TEMPOL or SQ-29548 increased extraction, while adrenoreceptor blockade was without effect (Panel C). Integrating blood flow and extraction, oxygen uptake at the gastrocnemius muscle was reduced in OZR versus LZR, and only combined treatment of OZR with all three agents (phentolamine, TEMPOL and SQ-29548) resulted in a significant improvement to muscle $\mathrm{VO}_{2}$. In preliminary experiments, treatment of LZR with phentolamine, TEMPOL and/or SQ-29548 failed to elicit a consistent and/or significant change in the above parameters (data not shown).

In response to $1 \mathrm{~Hz}$ twitch contractions (Figure 5), the general patterns of the measured outcomes in the present study were not strikingly different than that presented in Figure 4. Femoral artery blood flow (Panel A) was reduced and vascular resistance (Panel B) was elevated in OZR versus LZR, and these alterations were corrected by pre-treatment with phentolamine (TEMPOL and SQ-29548 having no consistent measureable impact). In contrast, the reduction in oxygen extraction in OZR versus LZR (Panel C) was only ameliorated following treatment with either TEMPOL or SQ-29548, with only a trivial benefit provided by treatment with phentolamine. However, the recovery in $\mathrm{VO}_{2}$ in contracting gastrocnemius of OZR to levels determined in LZR was only realized following treatment of the animal with all three agents (Panel D). Muscle fatigue resistance mirrored 
the patterns in $\mathrm{VO}_{2}$, with a reduced tension development after three minutes of contraction in OZR as compared to LZR, and a significant improvement in contractile performance only occurring following combined treatment of OZR with phentolamine, TEMPOL and SQ-29548 (Panel E).

Figure 6 summarizes hemodynamic responses in gastrocnemius muscle of LZR and OZR in response to three minutes of contraction at $3 \mathrm{~Hz}$. While femoral blood flow was lower (Panel A) and vascular resistance was higher (Panel B) in OZR versus LZR, the ability of phentolamine to restore these values was less robust than at lower levels of metabolic demand, with neither TEMPOL nor SQ-29548 exerting a discernible impact on these outcomes. In contrast, both TEMPOL and SQ-29548 improved oxygen extraction (Panel C) and $\mathrm{VO}_{2}$ (Panel D) across gastrocnemius muscle of OZR, while phentolamine exerted only minimal benefits. Phentolamine was unable to improve skeletal muscle fatigue resistance in OZR at $3 \mathrm{~Hz}$, while both TEMPOL and SQ-29548 did result in a mild improvement to performance, and combined treatment with all three agents resulted in the greatest improvement in the ability of the gastrocnemius muscle to maintain developed tension (Panel E).

Data describing the perfusion responses of in situ gastrocnemius muscle of OZR and LZR in response to $5 \mathrm{~Hz}$ contraction are summarized in Figure 7. These data appear present a different conceptual framework, as no employed intervention was able to improve femoral artery blood flow in OZR above that identified under control conditions (Panel A), and this was paralleled by measures of vascular resistance, which were very consistent across OZR groups, regardless of intervention (Panel B). However, treatment with TEMPOL or SQ-29548 improved oxygen extraction (Panel C) to levels similar to that in LZR, and $\mathrm{VO}_{2}$ as well (Panel D), although this improvement was constrained by the limits on normalized muscle $\mathrm{O}_{2}$ conductance (Panel E). Finally, while treatment of OZR with phentolamine was without effect on muscle fatigue resistance at $5 \mathrm{~Hz}$, and both TEMPOL and SQ-29548 resulted in mild improvements, combined therapy with all agents significantly improved muscle performance in OZR over that determined under control conditions (Panel F). In preliminary experiments, treatment of LZR with phentolamine, TEMPOL and/or SQ-29548 failed to elicit a consistent and/or significant change in the above parameters across levels of metabolic demand (data not shown).

The robust correlative relationships between skeletal muscle $\mathrm{O}_{2}$ conductance and muscle performance at $5 \mathrm{~Hz}$ contraction for LZR and OZR under the conditions of the present study are shown in Figure 8. $\mathrm{DmO}_{2}$ was a strong correlate of muscle fatigue resistance across LZR and OZR, with an r-squared value explaining nearly $60 \%$ of the variability in the data.

\section{DISCUSSION}

One of the most vexing challenges to public health and the quality of life of afflicted individuals is the insidious progression of peripheral vascular disease (PVD), with its characteristic impairment to blood flow delivery and the accelerated development of fatigue in those muscles experiencing an increased metabolic demand (Baron, 2002; Hudlicka and Brown, 2009; Nicholson et al. 1992; Ruiter et al. 2010; Wolfram et al. 2001). The OZR, with its inherent development of obesity, insulin resistance, moderate hypertension and hyperlipidemia represents an excellent model of non-atherosclerotic PVD risk, and while there have been numerous studies describing alterations to vascular reactivity, microvascular network structure and microvessel wall mechanics in OZR, the ability to extend these observations to an integrated system for the regulation of blood flow has been far more limited. While several studies have indicated that functional dilation (Xiang et al. 2008; 2006) or hyperemia (Frisbee, 2004; 2003) are impaired in skeletal muscle of OZR as 
compared to LZR, these remain superficially described, and results from recent study suggests that the integration across vascular structure/function relationships, the regulation of perfusion, functional hyperemia and skeletal muscle fatigue resistance may be more complicated than has previously been appreciated (Frisbee et al. 2009).

The initial observations from the first section of this study demonstrate that the increased resistance across the skeletal muscle microcirculation of OZR is multi-factorial in nature. While the adrenergic component to this elevated resistance can be effectively removed with $\alpha_{1} / \alpha_{2}$ adrenoreceptor blockade (Figure 1 ), this is clearly a more complicated process, and one that appears to involve alterations to endothelial function. While data in Figure 2 suggest that vascular responses to $\mathrm{TxA}_{2}$ are not altered in OZR, supporting earlier observations (Goodwill et al. 2008), previous studies provided compelling evidence that vascular production of $\mathrm{TxA}_{2}$, elevated in OZR (Xiang et al. 2008;2006), can compromise functional dilation and hyperemic responses within the distal microcirculation (where contribution to overall resistance is lower; Greene et al. 1989) (Frisbee et al. 2009;Xiang et al. 2008;2006). Additionally, the muted response to the endothelium-dependent agonist methacholine in OZR was partially ameliorated by pre-treatment with the antioxidant TEMPOL (and was consistently abolished by the nitric oxide synthase inhibitor L-NAME), clearly indicating the impairments to nitric oxide bioavailability through oxidant scavenging, an especially compelling issue for several reasons. Not only does elevated systemic oxidant stress in OZR have the capacity to severely compromise nitric oxide bioavailability, it also has the capacity to alter arachidonic acid metabolism leading toward the increased generation of TxA 2 (Goodwill et al. 2008;Zou, 2007;Zou et al. 2004). While these can obviously have immediate impacts on vascular tone regulation themselves, alterations in NO and $\mathrm{TxA}_{2}$ bioavailability in the microcirculation of OZR have also been demonstrated to contribute to significant changes to the patterns and severity of adrenergic constriction (Stepp and Frisbee, 2002), myogenic activation (Frisbee et al.2002), and the integration of these parameters for the determination of net vascular tone (Frisbee et al. 2009).

The second portion of this study focused on relationships between vascular function, blood flow and muscle fatigue resistance in OZR under control conditions and in response to the imposed interventions of phentolamine, TEMPOL and SQ-29548. As compared to LZR, OZR exhibited a blunted functional hyperemia and an elevated vascular resistance across gastrocnemius muscle across the continuum of metabolic demand. Interestingly, this was also accompanied by a reduction in oxygen extraction and a compromised $\mathrm{VO}_{2}$ in OZR, which, not surprisingly, was strongly predictive of an impaired muscle performance. This is a particularly intriguing outcome for multiple reasons. The gastrocnemius muscle was driven to contract via electrical stimulation of the sciatic nerve, and not only were the stimulation parameters identical between strains, but gastrocnemius mass was also very similar, which should have minimized differences between metabolic demand and muscle performance between the two strains. Further, at this age, daily physical activity is very similar between LZR and OZR (Stepp et al. 2004), fiber type profiles are similar (Adachi $e t$ al. 2007; Pujol et al. 1993), and the maximum developed tension was nearly identical between the two strains (Table 1). As such, results from these experiments strongly suggest that impairments to muscle performance in OZR at this age appear to reflect an altered behavior within blood delivery/distribution in the microcirculation (i.e. $\mathrm{O}_{2}$ flux across the working muscle), rather than overt dysfunction within skeletal muscle myocyte and motor unit recruitment patterns. However, it must be emphasized that these conclusions are relevant for OZR at this age only, as previous studies have clearly demonstrated significant, although variable, alterations to contractile and metabolic functions of skeletal muscle myocytes in OZR afflicted with the metabolic syndrome with increasing age (Campion et al. 1987; Farkas et al. 1994; He et al. 1995). 
At the lower end of this continuum of metabolic demand, blood flow to gastrocnemius muscle of OZR was restrained by increased adrenergic tone, as infusion of phentolamine abolished the elevated vascular resistance (Figures 4 and 5). However, adrenergic constraint appeared to play little role in terms of the poor oxygen extraction and $\mathrm{VO}_{2}$, as these were unaffected by phentolamine infusion. In contrast, the endothelial dysfunction in OZR was not a significant contributor to perfusion resistance across the gastrocnemius muscle, as neither TEMPOL nor SQ-29548 altered femoral artery blood flow. What was most compelling was that TEMPOL and SQ-29548 improved oxygen extraction across the gastrocnemius of OZR as compared to LZR, although $\mathrm{VO}_{2}$ remained low owing to the lack of an impact on blood flow. These relationships were also evident in the gastrocnemius of OZR working at $3 \mathrm{~Hz}$ contractions (Figure 6), wherein the influence of phentolamine, while decreased with elevated metabolic demand, was primarily via reduced blood flow resistance while TEMPOL and SQ-29548 improved oxygen extraction, and the combined influence of all three agents improving $\mathrm{VO}_{2}$ and muscle performance to the greatest extent. The condition at $5 \mathrm{~Hz}$ (Figure 7) contractions was somewhat different owing to the structural remodeling of the microvessel wall and networks to impose an upper 'ceiling' on bulk blood flow to the muscle in OZR (Frisbee, 2005). As such, phentolamine was without effect on resistance in OZR, although its restrictive effect was diminishing with increased contraction frequency owing to metabolic sympatholysis (Frisbee, 2004). However, TEMPOL and SQ-29548 retained their ability to improve oxygen extraction and conductance such that an optimal muscle $\mathrm{VO}_{2}$ under these conditions in OZR was realized. Not surprisingly, regardless of metabolic demand, optimization of bulk blood flow, muscle oxygen conductance in OZR, specifically following treatment with all three pharmacological agents, was associated with the greatest improvement to gastrocnemius muscle fatigue resistance.

Taken together, the results of the present study have three significant and novel implications. The first of these is the altering blood flow alone cannot restore skeletal muscle performance within the OZR model of PVD. This observation is in some contrast to the accepted interpretations of PVD, wherein a consistent assumption is that improving blood flow to active tissue, and certainly in proportion to the continuum of metabolic demand (i.e. $\mathrm{O}_{2}$ uptake), would improve functional outcomes. That an intervention which enhanced functional hyperemia was ineffective at improving muscle oxygen conductance and performance emphasizes the complexity of the processes affecting the diffusional conductance of oxygen that is central to the poor outcomes identified in OZR and the strong relationship determined between muscle $\mathrm{O}_{2}$ conductance and the fatigue response (Figure $8)$.

Importantly, treatment of OZR with TEMPOL or SQ-29548 improved oxygen flux across the microcirculation of the gastrocnemius muscle with minimal impact on aggregate vascular resistance. This observation suggests that the beneficial impact of improving endothelial function with regard to enhancing the integrated outcome of muscle performance may be the result of optimizing hemodynamic behavior in the distal microcirculation (where localized mass transport and exchange phenomena are most relevant) than in the proximal microcirculation (where the regulation of perfusion resistance is most relevant). This observation is be supported by the muscle performance data in the present study, wherein neither phentolamine nor TEMPOL/SQ-29548 alone improved muscle performance, while only combined treatment with all three agents reduced fatigue development. This apparent spatial distinction of the major contributors to poor perfusion and muscle performance outcomes, with the beneficial impacts of adrenoreceptor blockade being primarily relevant in the proximal microcirculation and those for improved endothelial dysfunction being primarily relevant in the distal microcirculation represents the second major implication and novel observation of the results present study. 
The concept involving the spatial relevance of interventions suggests the third major implication of the present study. The results of the previous study indicated that one of the hallmark characteristics of the distal microcirculation within in situ cremaster muscle of OZR was that perfusion distribution at microvascular bifurcations was more heterogeneous than in LZR, with potential contributors to this derangement being elevated oxidant stress and increased $\mathrm{TxA}_{2}$ production (Frisbee et al. 2009). Speculatively, this may be the underlying physiological/hemodynamic mechanism for the impact of TEMPOL/SQ-29548 on improving oxygen flux in contracting muscle of OZR in the present study. If development of PVD in OZR is characterized by an increasing perfusion heterogeneity at microvascular bifurcations, resulting in a poor pattern of oxygen extraction across the muscle through an increasing propensity for 'high flow pathways' with lower extraction and 'low flow pathways' which become flow-limited, this could compromise net oxygen extraction and be reflective of a generalized impairment to mass transport and exchange across the skeletal muscle microcirculation. Indeed, this process is akin to matching of ventilation and perfusion in the lung, which is known to be an important determinant in transfer of $\mathrm{O}_{2}$ (i.e. $\mathrm{O}_{2}$ conductance) from alveolar gas into blood. Further interrogation of the contributing physiological, biochemical and molecular signaling mechanisms, their spatio-temporal distribution, their interactions, and the potential for ameliorative intervention appears to be well justified.

While the results of this study provide for a compelling framework for the interrogation of the relationships between perfusion and fatigue in skeletal muscle under conditions of the metabolic syndrome, one inherent limitation that should be acknowledged is the preparation itself. The combination of a barbiturate anesthetic, which can inhibit reflex sympathetic excitation as a result of the muscle contraction, clearly has the potential to impact the results of study in an unpredictable manner. Further, the potential for electrical activation of sympathetic postganglionic fibers and group IV afferents as a result of the current applied to the sciatic nerve cannot fully be discounted. Given these inherent limitations to the preparation, further effort into the verification and potential application of a decerebrate preparation without the necessity of anesthesia where the skeletal muscles in question can be activated via direct stimulation of ventral roots may be warranted.

\section{Acknowledgments}

This study was supported by grants from the National Institutes of Health (NIH DK R01 64668; RR2865AR) and the American Heart Association (AHA SDG 0330194N and EIA 0740129N to JCF and BGIA 3630002 to IMO). The authors also wish to express their gratitude for the expert technical assistance of Mr. Tianjian Huang from the Department of Physiology at the Medical College of Wisconsin, Ms. Milinda James from the Department of Physiology and Pharmacology and Ms. Sarah Olenich from the Division of Exercise Physiology at West Virginia University and for support provided through the Translational Research Facility in the Center for Cardiovascular and Respiratory Sciences at the West Virginia University HSC. The authors express their gratitude to Dr. Peter D. Wagner from the University of California at San Diego Medical Center for his helpful insights and suggestions regarding the determination of oxygen conductance.

\section{LITERATURE CITED}

1. Adachi T, Kikuchi N, Yasuda K, Anahara R, Gu N, Matsunaga T, Yamamura T, Mori C, Tsujimoto G, Tsuda K, Ishihara A. Fibre type distribution and gene expression levels of both succinate dehydrogenase and peroxisome proliferator-activated receptor-gamma coactivator-1alpha of fibres in the soleus muscle of Zucker diabetic fatty rats. Exp Physiol. 2007; 92(2):449-55. [PubMed: 17158179]

2. Baron AD. Insulin resistance and vascular function. J Diabetes Complications. 2002; 16(1):92-102. [PubMed: 11872375]

3. Bouvet C, Belin de Chantemèle E, Guihot AL, Vessières E, Bocquet A, Dumont $\mathrm{O}$, Jardel A, Loufrani L, Moreau P, Henrion D. Flow-induced remodeling in resistance arteries from obese 
Zucker rats is associated with endothelial dysfunction. Hypertension. 2007; 50(1):248-54. [PubMed: 17515452]

4. Campion DR, Shapira JF, Allen CE, Hausman GJ, Martin RJ. Metabolic characteristics of skeletal muscle from lean and obese Zucker rats. Growth. 1987; 51(4):397-410. [PubMed: 3450549]

5. Cannon CP. Mixed dyslipidemia, metabolic syndrome, diabetes mellitus, and cardiovascular disease: clinical implications. Am J Cardiol. 2008; 102(12A):5L-9L.

6. Farkas GA, Gosselin LE, Zhan WZ, Schlenker EH, Sieck GC. Histochemical and mechanical properties of diaphragm muscle in morbidly obese Zucker rats. J Appl Physiol. 1994; 77(5):2250-9. [PubMed: 7868442]

7. Ford ES, Mokdad AH. Epidemiology of obesity in the Western Hemisphere. J Clin Endocrinol Metab. 2008; 93(11 Suppl 1):S1-S8. [PubMed: 18987267]

8. Frisbee JC, Hollander JM, Brock RW, Yu HG, Boegehold MA. Integration of skeletal muscle resistance arteriolar reactivity for perfusion responses in the metabolic syndrome. Am J Physiol Regul Integr Comp Physiol. 2009; 296(6):R1771-82. [PubMed: 19386988]

9. Frisbee JC. Reduced nitric oxide bioavailability contributes to skeletal muscle microvessel rarefaction in the metabolic syndrome. Am J Physiol Regul Integr Comp Physiol. 2005; 289(2):R307-R316. [PubMed: 15802560]

10. Frisbee JC. Impaired hemorrhage tolerance in the obese Zucker rat model of metabolic syndrome. $\mathrm{J}$ Appl Physiol. 2006; 100(2):465-73. [PubMed: 16223976]

11. Frisbee JC. Enhanced arteriolar alpha-adrenergic constriction impairs dilator responses and skeletal muscle perfusion in obese Zucker rats. J Appl Physiol. 2004; 97(2):764-72. [PubMed: 15075303]

12. Frisbee JC. Impaired skeletal muscle perfusion in obese Zucker rats. Am J Physiol Regul Integr Comp Physiol. 2003; 285(5):R1124-34. [PubMed: 12855417]

13. Frisbee JC, Maier KG, Stepp DW. Oxidant stress-induced increase in myogenic activation of skeletal muscle resistance arteries in obese Zucker rats. Am J Physiol Heart Circ Physiol. 2002; 283(6):H2160-8. [PubMed: 12388303]

14. Goodwill AG, Frisbee SJ, Stapleton PA, James ME, Frisbee JC. Impact of chronic anticholesterol therapy on development of microvascular rarefaction in the metabolic syndrome. Microcirculation. 2009; 16(8):667-84. [PubMed: 19905967]

15. Goodwill AG, James ME, Frisbee JC. Increased vascular thromboxane generation impairs dilation of skeletal muscle arterioles of obese Zucker rats with reduced oxygen tension. Am J Physiol Heart Circ Physiol. 2008; 295(4):H1522-8. [PubMed: 18689495]

16. Greene AS, Tonellato PJ, Lui J, Lombard JH, Cowley AW Jr. Microvascular rarefaction and tissue vascular resistance in hypertension. Am J Physiol. 1989; 256(1 Pt 2):H126-31. [PubMed: 2912175]

17. Guerre-Millo M. Regulation of ob gene and overexpression in obesity. Biomed Pharmacother. 1997; 51(8):318-323. [PubMed: 9436523]

18. He D, Bolstad G, Brubakk A, Medbø JI. Muscle fibre type and dimension in genetically obese and lean Zucker rats. Acta Physiol Scand. 1995; 155(1):1-7. [PubMed: 8553871]

19. Hudlicka O, Brown MD. Adaptation of skeletal muscle microvasculature to increased or decreased blood flow: role of shear stress, nitric oxide and vascular endothelial growth factor. J Vasc Res. 2009; 46(5):504-12. [PubMed: 19556804]

20. Jones PH. Expert perspective: reducing cardiovascular risk in metabolic syndrome and type 2 diabetes mellitus beyond low-density lipoprotein cholesterol lowering. Am J Cardiol. 2008; 102(12A):41L-47L.

21. Katakam PV, Domoki F, Snipes JA, Busija AR, Jarajapu YP, Busija DW. Impaired mitochondriadependent vasodilation in cerebral arteries of Zucker obese rats with insulin resistance. Am J Physiol Regul Integr Comp Physiol. 2009; 296(2):R289-98. [PubMed: 19005015]

22. Kurdak SS, Grassi B, Wagner PD, Hogan MC. Blood flow distribution in working in situ canine muscle during blood flow reduction. J Appl Physiol. 1996; 80(6):1978-83. [PubMed: 8806904]

23. Lu X, Guo X, Karathanasis SK, Zimmerman KM, Onyia JE, Peterson RG, Kassab GS. Rosiglitazone reverses endothelial dysfunction but not remodeling of femoral artery in Zucker diabetic fatty rats. Cardiovasc Diabetol. 2010; 19:9, 19. 
24. Obunai K, Jani S, Dangas GD. Cardiovascular morbidity and mortality of the metabolic syndrome. Med Clin North Am. 2007; 91(6):1169-84. [PubMed: 17964915]

25. Naik JS, Xiang L, Hester RL. Enhanced role for RhoA-associated kinase in adrenergic-mediated vasoconstriction in gracilis arteries from obese Zucker rats. Am J Physiol Regul Integr Comp Physiol. 2006; 290(1):R154-61. [PubMed: 16141308]

26. Nicholson CD, Angersbach D, Wilke R. The effect of physical training on rat calf muscle, oxygen tension, blood flow, metabolism and function in an animal model of chronic occlusive peripheral vascular disease. Int J Sports Med. 1992; 13(1):60-4. [PubMed: 1544736]

27. Pujol A, Lefaucheur L, Ecolan P, Picon L, Penicaud L. Fiber type composition and enzyme activities of muscles in two models of obese rats. Comp Biochem Physiol B. 1993; 106(2):269-72. [PubMed: 8243055]

28. Roca J, Hogan MC, Story D, Bebout DE, Haab P, Gonzalez R, Ueno O, Wagner PD. Evidence for tissue diffusion limitation of VO2max in normal humans. J Appl Physiol. 1989; 67(1):291-9. [PubMed: 2759955]

29. Ruiter MS, van Golde JM, Schaper NC, Stehouwer CD, Huijberts MS. Diabetes impairs arteriogenesis in the peripheral circulation: review of molecular mechanisms. Clin Sci (Lond). 2010; 119(6):225-38. [PubMed: 20545627]

30. Schreihofer AM, Hair CD, Stepp DW. Reduced plasma volume and mesenteric vascular reactivity in obese Zucker rats. Am J Physiol Regul Integr Comp Physiol. 2005; 288(1):R253-61. [PubMed: 15345476]

31. Stepp DW, Pollock DM, Frisbee JC. Low-flow vascular remodeling in the metabolic syndrome X. Am J Physiol Heart Circ Physiol. 2004; 286(3):H964-70. [PubMed: 14644764]

32. Stepp DW, Frisbee JC. Augmented adrenergic vasoconstriction in hypertensive diabetic obese Zucker rats. Am J Physiol Heart Circ Physiol. 2002; 282(3):H816-20. [PubMed: 11834474]

33. Xiang L, Dearman J, Abram SR, Carter C, Hester RL. Insulin resistance and impaired functional vasodilation in obese Zucker rats. Am J Physiol Heart Circ Physiol. 2008; 294(4):H1658-66. [PubMed: 18296567]

34. Xiang L, Naik JS, Hodnett BL, Hester RL. Altered arachidonic acid metabolism impairs functional vasodilation in metabolic syndrome. Am J Physiol Regul Integr Comp Physiol. 2006; 290(1):R134-8. [PubMed: 16166209]

35. Wagner PD. Gas exchange and peripheral diffusion limitation. Med Sci Sports Exerc. 1992; 24(1): 54-8. [PubMed: 1548996]

36. Williams G, Bing C, Cai XJ, Harrold JA, King PJ, Liu XH. The hypothalamus and the control of energy homeostasis: different circuits, different purposes. Physiol Behav. 2001; 74(4-5):683-701. [PubMed: 11790431]

37. Wolfram RM, Budinsky AC, Sinzinger H. Assessment of peripheral arterial vascular disease with radionuclide techniques. Semin Nucl Med. 2001; 31(2):129-42. [PubMed: 11330784]

38. Zou MH. Peroxynitrite and protein tyrosine nitration of prostacyclin synthase. Prostaglandins Other Lipid Mediat. 2007; 82(1-4):119-127. [PubMed: 17164139]

39. Zou MH, Cohen R, Ullrich V. Peroxynitrite and vascular endothelial dysfunction in diabetes mellitus. Endothelium. 2004; 11(2):89-97. [PubMed: 15370068] 

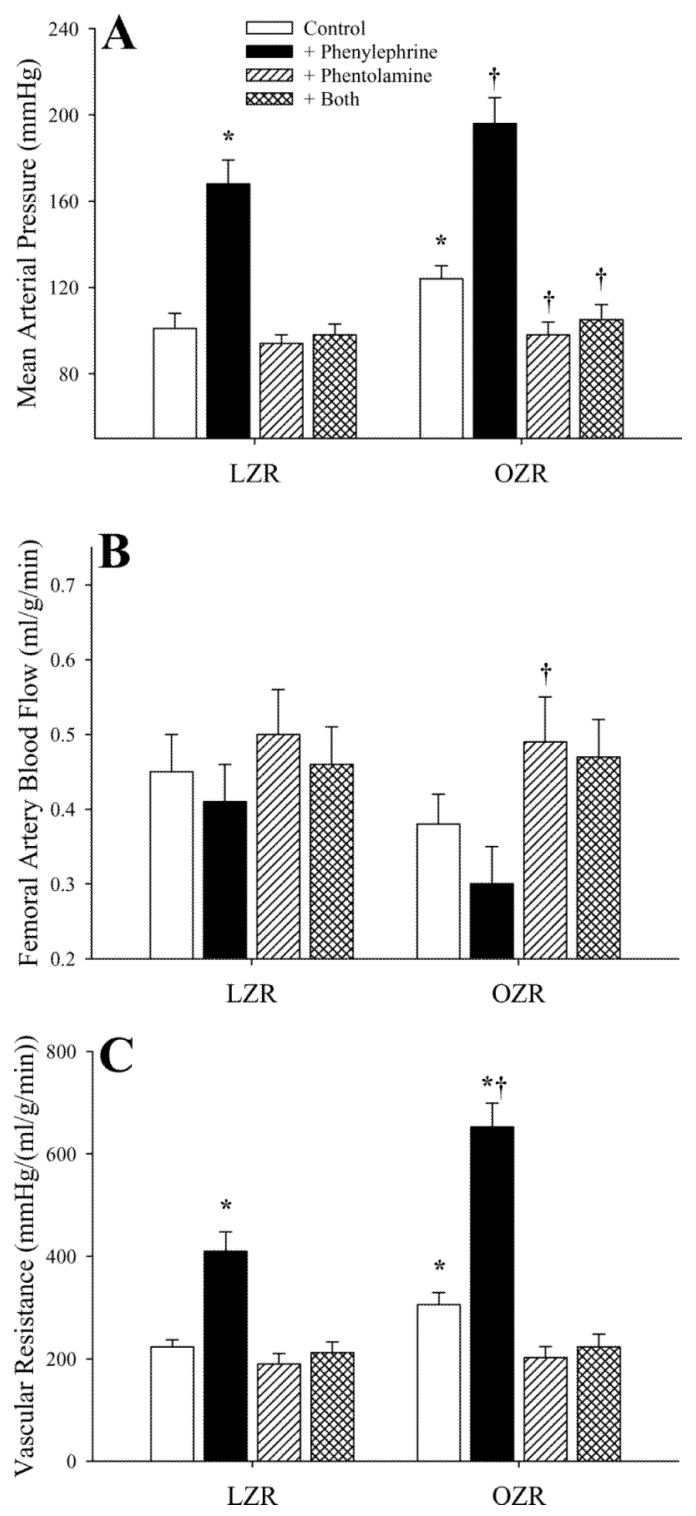

Figure 1.

Arterial pressor responses and gastrocnemius muscle perfusion in LZR and OZR following intravenous infusion of the adrenoreceptor agonist phenylephrine $(10 \mu \mathrm{g} / \mathrm{kg})$ under control conditions and in response to pre-treatment with the $\alpha_{1} / \alpha_{2}$ adrenoreceptor antagonist phentolamine $(10 \mathrm{mg} / \mathrm{kg})$. Data (mean $\pm \mathrm{SE}$ ) are presented for changes in mean arterial pressure (Panel A), femoral artery blood flow (Panel B) and vascular resistance across the gastrocnemius muscle (Panel C). ${ }^{*} \mathrm{p}<0.05$ vs. LZR; $\dagger \mathrm{p}<0.05$ vs. OZR; $\mathrm{n}=6$ animals under each condition. 


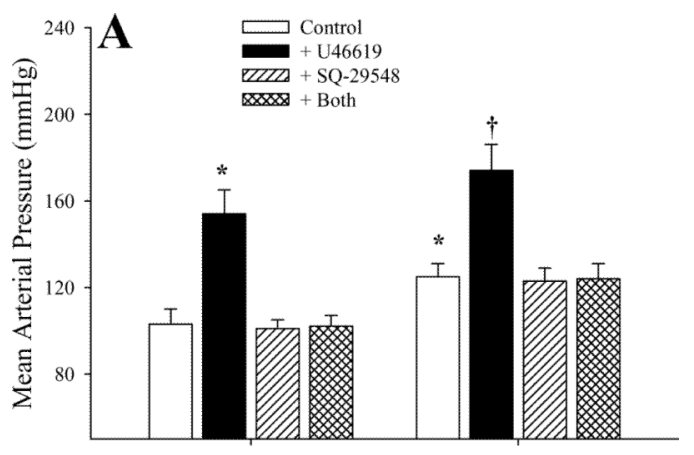

LZR

OZR
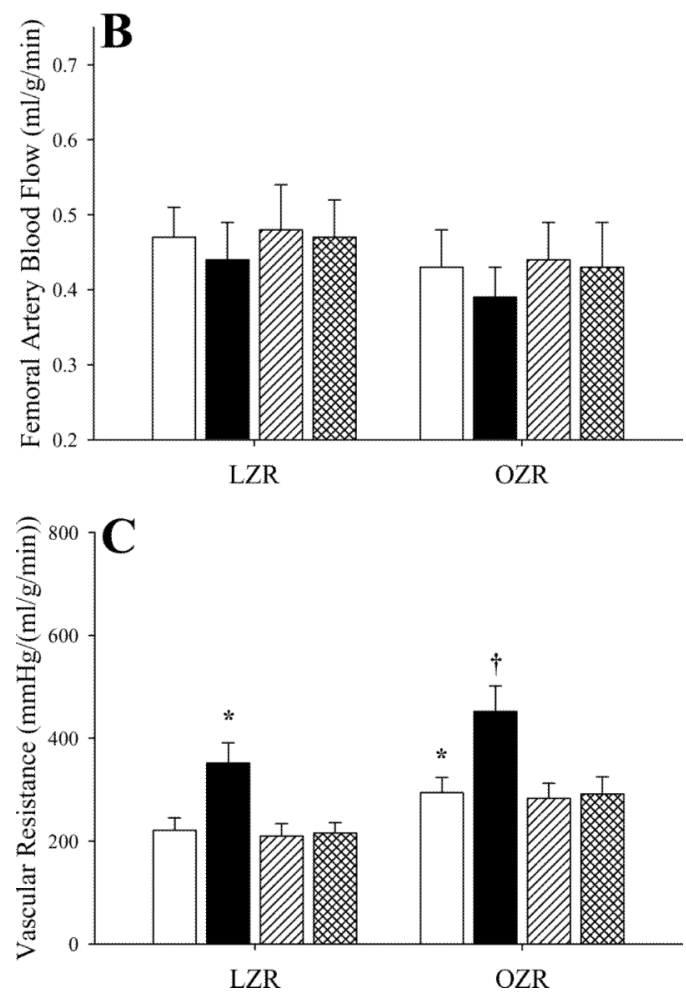

Figure 2.

Arterial pressor responses and gastrocnemius muscle perfusion in LZR and OZR following intravenous infusion of the TxA 2 mimetic U46619 $(10 \mu \mathrm{g} / \mathrm{kg})$ under control conditions and in response to pre-treatment with the $\mathrm{PGH}_{2} / \mathrm{TxA}_{2}$ receptor antagonist SQ-29548 (10 mg/kg). Data $($ mean \pm SE) are presented for changes in mean arterial pressure (Panel A), femoral artery blood flow (Panel B) and vascular resistance across the gastrocnemius muscle (Panel C). $* \mathrm{p}<0.05$ vs. LZR; $\dagger \mathrm{p}<0.05$ vs. OZR; $\mathrm{n}=6$ animals under each condition. 

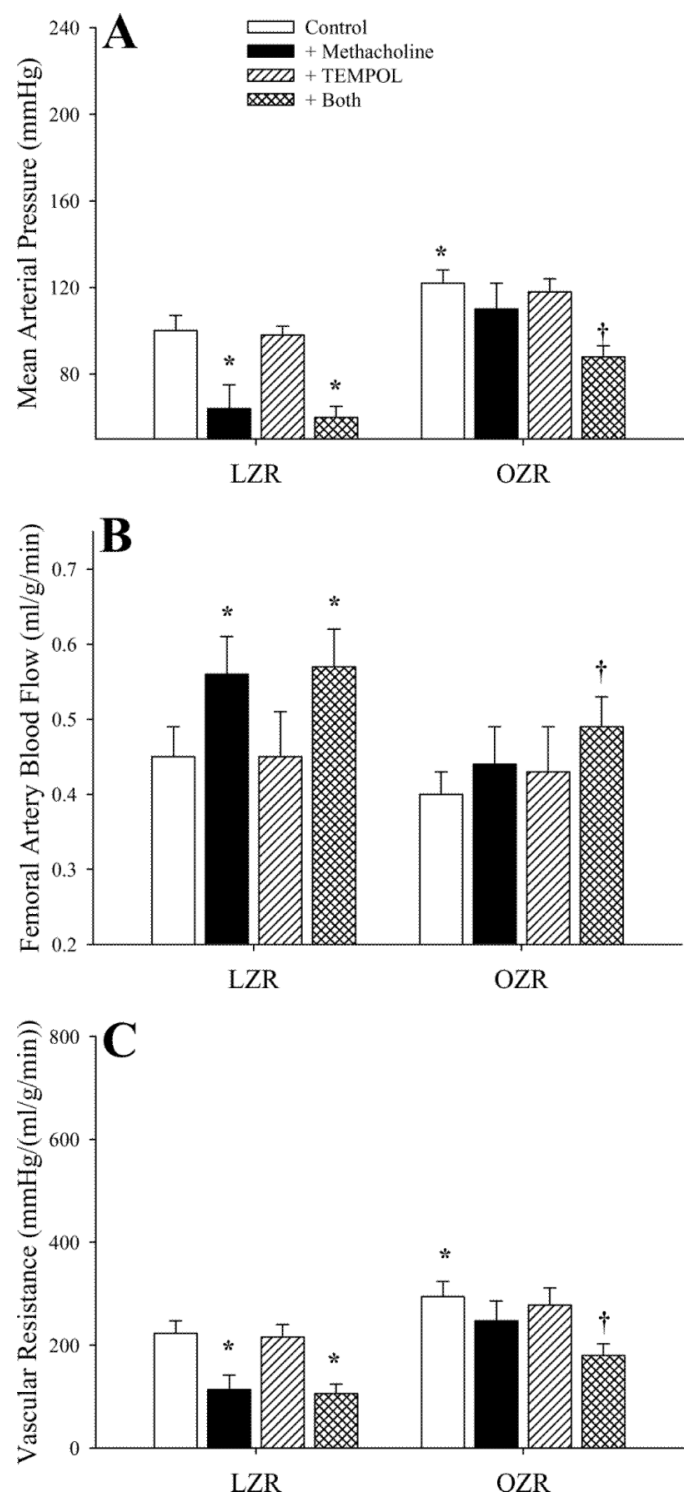

Figure 3.

Arterial pressor responses and gastrocnemius muscle perfusion in LZR and OZR following intravenous infusion of the endothelium-dependent dilator agonist methacholine $(10 \mu \mathrm{g} / \mathrm{kg})$ under control conditions and in response to pre-treatment with the superoxide dismutase mimetic TEMPOL $(50 \mathrm{mg} / \mathrm{kg})$. Data $($ mean $\pm \mathrm{SE})$ are presented for changes in mean arterial pressure (Panel A), femoral artery blood flow (Panel B) and vascular resistance across the gastrocnemius muscle (Panel C). $* \mathrm{p}<0.05$ vs. LZR; $\dagger \mathrm{p}<0.05$ vs. OZR; $\mathrm{n}=6$ animals under each condition. 

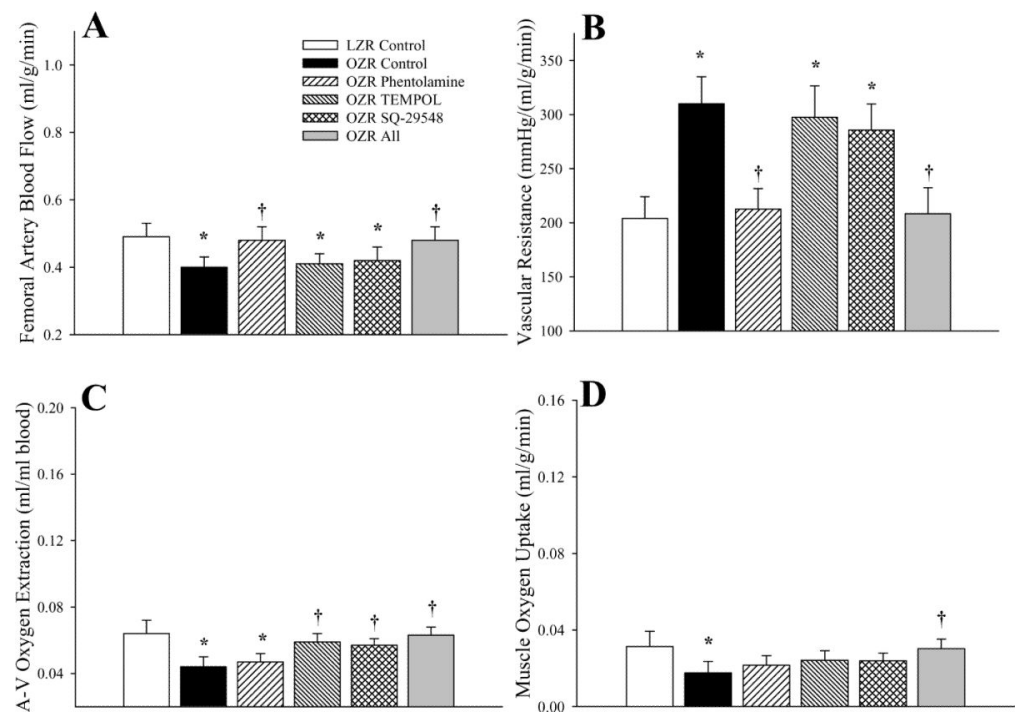

Figure 4.

Hemodynamic and oxygen uptake responses across gastrocnemius muscle of LZR and OZR under resting conditions. Data $(m e a n \pm S E$ ) are presented for femoral artery blood flow (Panel A), vascular resistance across the gastrocnemius muscle (Panel B), oxygen extraction (Panel C) and oxygen uptake $\left(\mathrm{VO}_{2}\right)$ by the muscle (Panel D). Values are presented under control conditions and following treatment of OZR with phentolamine $(10 \mathrm{mg} / \mathrm{kg})$, TEMPOL $(50$ $\mathrm{mg} / \mathrm{kg}), \mathrm{SQ}-29548(10 \mathrm{mg} / \mathrm{kg})$ or all three substances. ${ }^{*} \mathrm{p}<0.05 \mathrm{vs}$. LZR ( $\mathrm{n}=5$ animals $) ; \dagger$ $\mathrm{p}<0.05$ vs. OZR ( $\mathrm{n}=15$ for control; $\mathrm{n}=5$ for each treatment group; all oxygen extraction and $\mathrm{VO}_{2}$ data are from $\mathrm{n}=5$ animals). The legend for all panels is presented in Panel A. 

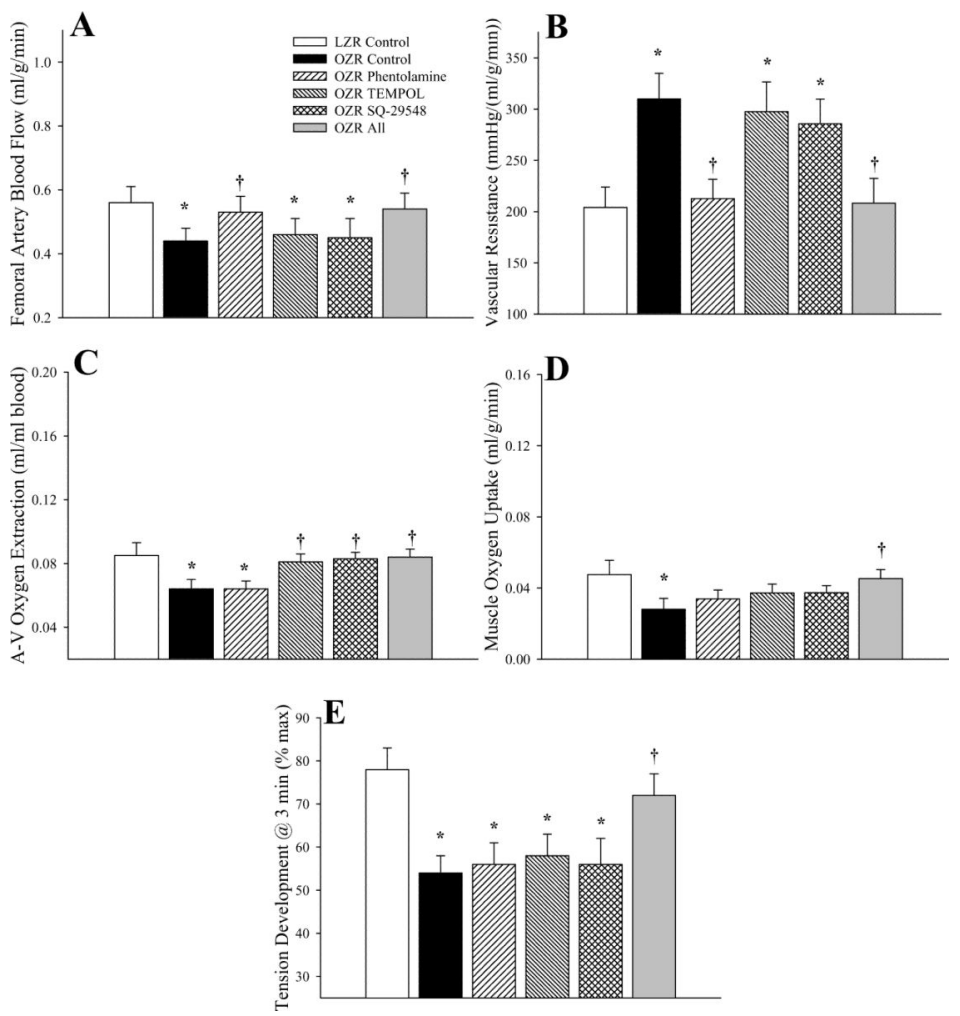

Figure 5.

Hemodynamic and oxygen uptake responses across gastrocnemius muscle of LZR and OZR in response to three minutes of $1 \mathrm{~Hz}$ muscle contraction. Data (mean $\pm \mathrm{SE}$ ) are presented for femoral artery blood flow (Panel A), vascular resistance across the gastrocnemius muscle (Panel B), oxygen extraction (Panel C), oxygen uptake $\left(\mathrm{VO}_{2}\right)$ by the muscle (Panel D) and developed tension by the gastrocnemius (Panel E). Values are presented under control conditions and following treatment of OZR with phentolamine $(10 \mathrm{mg} / \mathrm{kg})$, TEMPOL (50 $\mathrm{mg} / \mathrm{kg}), \mathrm{SQ}-29548(10 \mathrm{mg} / \mathrm{kg})$ or all three substances. $* \mathrm{p}<0.05 \mathrm{vs}$. LZR ( $\mathrm{n}=5$ animals $) ; \dagger$ $\mathrm{p}<0.05$ vs. OZR ( $\mathrm{n}=15$ for control; $\mathrm{n}=5$ for each treatment group; all oxygen extraction and $\mathrm{VO}_{2}$ data are from $\mathrm{n}=5$ animals). The legend for all panels is presented in Panel A. 

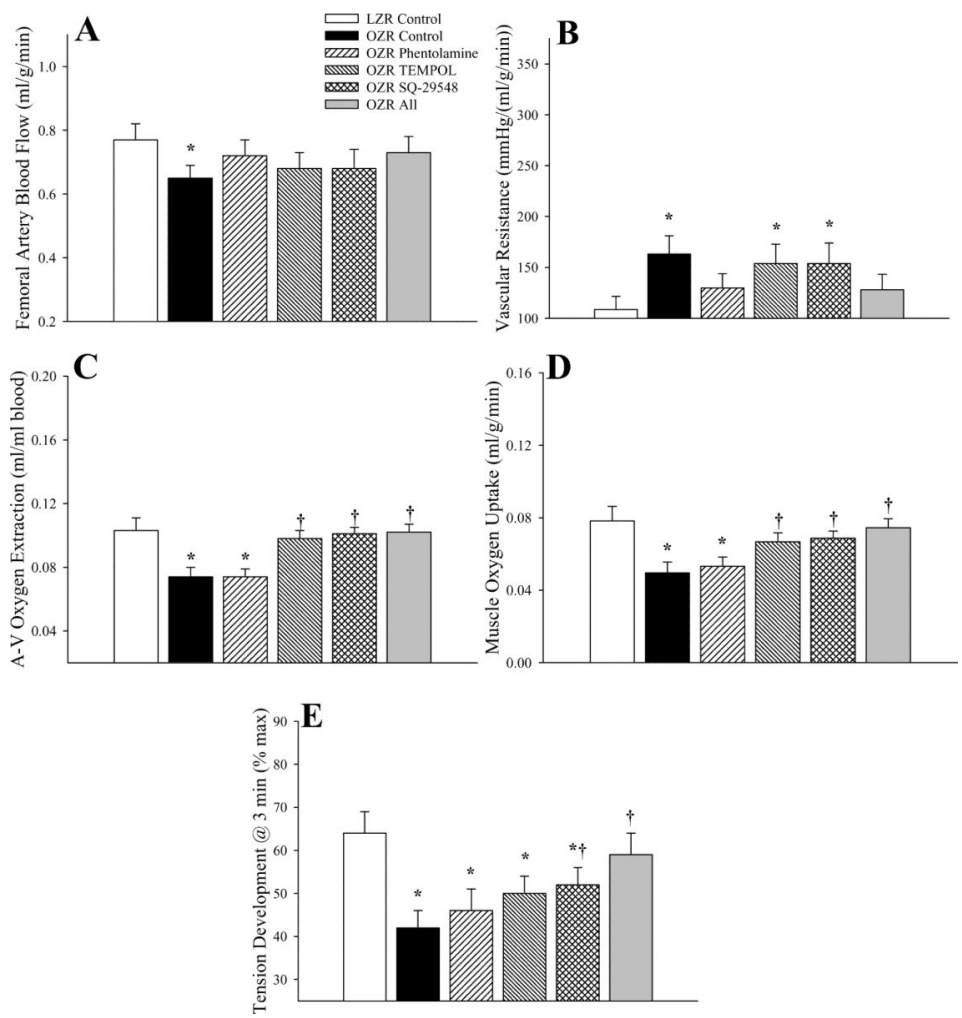

Figure 6.

Hemodynamic and oxygen uptake responses across gastrocnemius muscle of LZR and OZR in response to three minutes of $3 \mathrm{~Hz}$ muscle contraction. Data (mean $\pm \mathrm{SE}$ ) are presented for femoral artery blood flow (Panel A), vascular resistance across the gastrocnemius muscle (Panel B), oxygen extraction (Panel C), oxygen uptake $\left(\mathrm{VO}_{2}\right)$ by the muscle (Panel D) and developed tension by the gastrocnemius (Panel E). Values are presented under control conditions and following treatment of OZR with phentolamine $(10 \mathrm{mg} / \mathrm{kg})$, TEMPOL (50 $\mathrm{mg} / \mathrm{kg}), \mathrm{SQ}-29548(10 \mathrm{mg} / \mathrm{kg})$ or all three substances. ${ }^{*} \mathrm{p}<0.05$ vs. LZR ( $\mathrm{n}=5$ animals); $\dagger$ $\mathrm{p}<0.05$ vs. OZR ( $\mathrm{n}=15$ for control; $\mathrm{n}=5$ for each treatment group; all oxygen extraction and $\mathrm{VO}_{2}$ data are from $\mathrm{n}=5$ animals). The legend for all panels is presented in Panel A. 

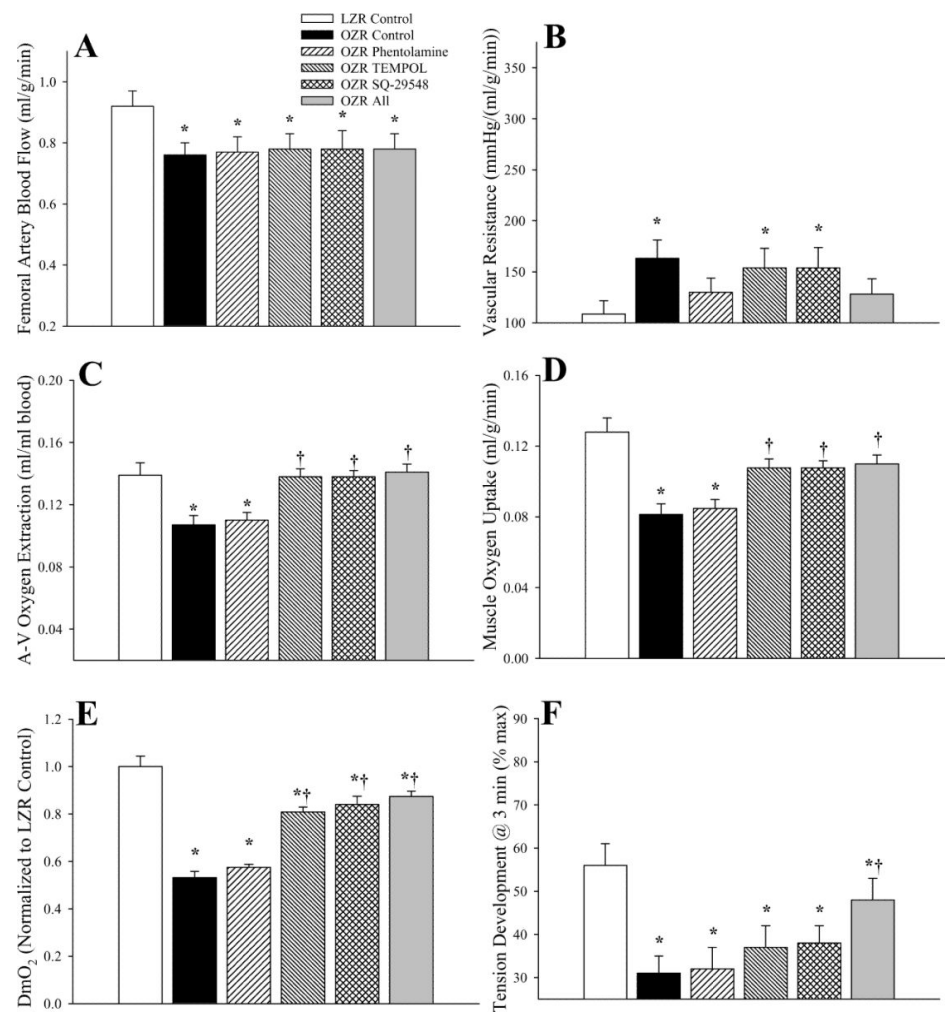

Figure 7.

Hemodynamic and oxygen uptake responses across gastrocnemius muscle of LZR and OZR in response to three minutes of $5 \mathrm{~Hz}$ muscle contraction. Data (mean $\pm \mathrm{SE}$ ) are presented for femoral artery blood flow (Panel A), vascular resistance across the gastrocnemius muscle (Panel B), oxygen extraction (Panel C), oxygen uptake $\left(\mathrm{VO}_{2}\right)$ by the muscle (Panel D), normalized $\mathrm{O}_{2}$ conductance across the muscle (Panel $\mathrm{E}$ ) and developed tension by the gastrocnemius (Panel F). Values are presented under control conditions and following treatment of OZR with phentolamine $(10 \mathrm{mg} / \mathrm{kg})$, TEMPOL (50 mg/kg), SQ-29548 (10 mg/ $\mathrm{kg}$ ) or all three substances. $* \mathrm{p}<0.05$ vs. LZR ( $\mathrm{n}=5$ animals); $\dagger \mathrm{p}<0.05$ vs. OZR ( $\mathrm{n}=15$ for control; $\mathrm{n}=5$ for each treatment group; all oxygen extraction and $\mathrm{VO}_{2}$ data are from $\mathrm{n}=5$ animals). The legend for all panels is presented in Panel B. 


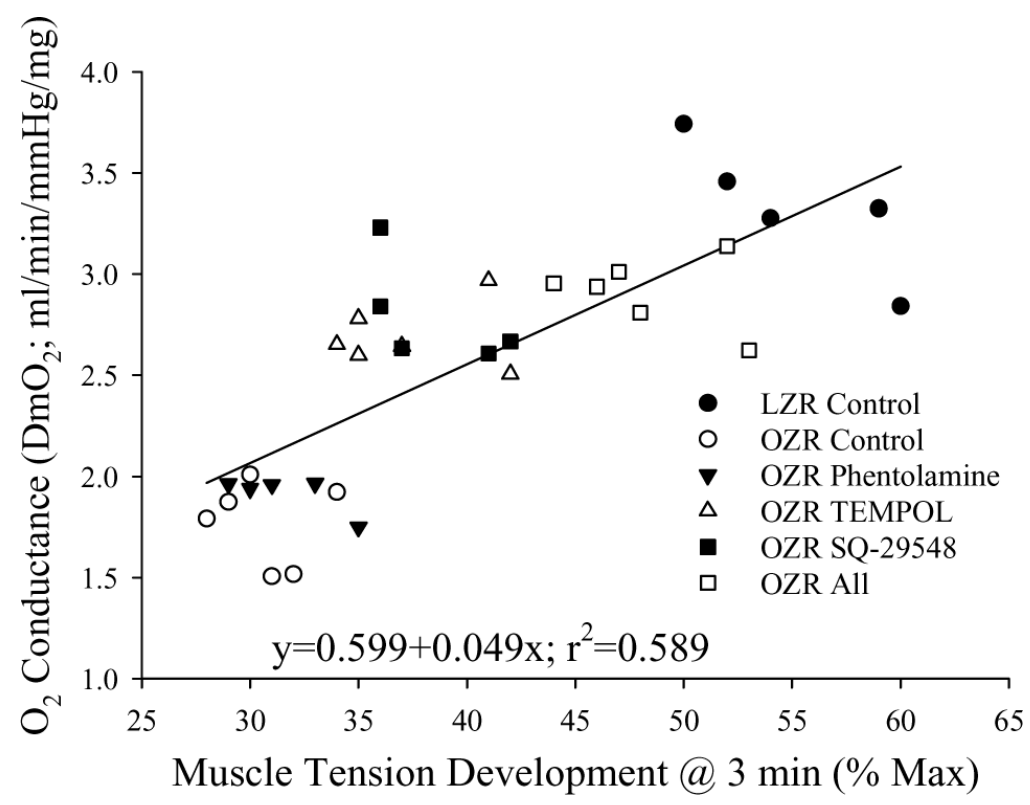

Figure 8.

Correlation between $\mathrm{O}_{2}$ conductance $\left(\mathrm{DmO}_{2}\right)$ and muscle performance in LZR $(\mathrm{n}=5)$ and OZR $(n=5-6)$ in response to three minutes of muscle contraction at a frequency of $5 \mathrm{~Hz}$. Values are presented under control conditions and following treatment of OZR with phentolamine $(10 \mathrm{mg} / \mathrm{kg})$, TEMPOL $(50 \mathrm{mg} / \mathrm{kg}), \mathrm{SQ}-29548(10 \mathrm{mg} / \mathrm{kg})$ or all three substances. Data are presented for individual animals and the equation for the line of best fit is determined using a least squares analysis. 
Table 1

Baseline characteristics of 15-17 week-old LZR and OZR used in the present study.

\begin{tabular}{lcc}
\hline & LZR & OZR \\
\hline Mass $(\mathrm{g})$ & $366 \pm 8$ & $684 \pm 11^{*}$ \\
MAP $(\mathrm{mmHg})$ & $101 \pm 5$ & $124 \pm 6^{*}$ \\
{$[\text { Glucose }]_{\text {plasma }}(\mathrm{mg} / \mathrm{dl})$} & $111 \pm 10$ & $184 \pm 14^{*}$ \\
{$[\text { Insulin }]_{\text {plasma }}(\mathrm{ng} / \mathrm{ml})$} & $2.0 \pm 0.4$ & $9.4 \pm 1.1^{*}$ \\
{$[\text { Cholesterol }]_{\text {plasma }}(\mathrm{mg} / \mathrm{dl})$} & $78 \pm 9$ & $138 \pm 12^{*}$ \\
{$[\text { Triglycerides }]_{\text {plasma }}(\mathrm{mg} / \mathrm{dl})$} & $84 \pm 11$ & $348 \pm 19^{*}$ \\
{$[\text { Nitrotyrosine }]_{\text {plasma }}(\mathrm{ng} / \mathrm{ml})$} & $14 \pm 4$ & $48 \pm 8^{*}$ \\
Maximum Tension Development $(\mathrm{g} / \mathrm{g})$ & $384 \pm 28$ & $369 \pm 27$ \\
\hline
\end{tabular}

p $<0.05$ versus LZR. 


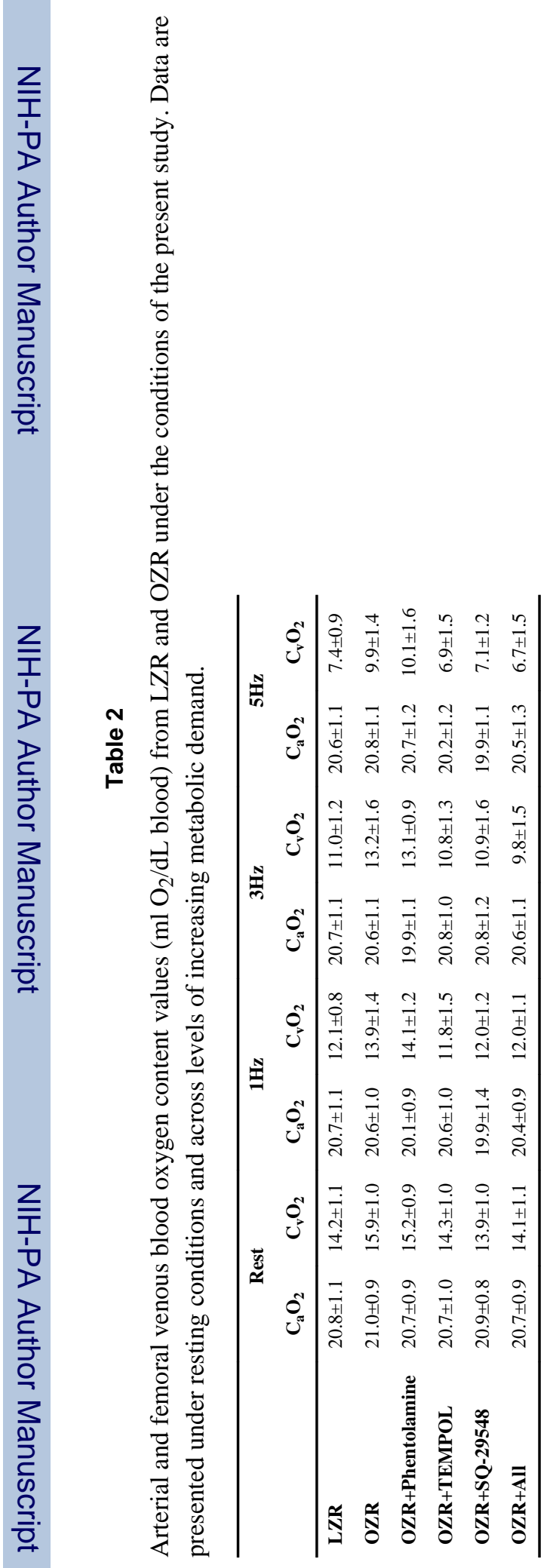
Exp Physiol. Author manuscript; available in PMC 2012 March 1. 